\title{
SHAKESPEARE: criador e criatura
}

\author{
Marlene Soares dos Santos \\ (UFRJ) \\ https://orcid.org/0000-0003-3165-7606
}

\section{RESUMO}

No auge da popularidade e prestígio do teatro elisabetano-jaimesco, William Shakespeare (1564-1616) era um autor como muitos outros. Depois que ele se aposentou em 1611, outros dramaturgos continuaram produzindo peças que asseguravam a merecida fama de excelência desse teatro. Em 1623, a publicação do chamado First Folio, que reunia todas as peças shakespearianas, reacendeu o interesse pelo dramaturgo. Entretanto, o fechamento dos teatros pelo governo puritano em 1642 causou um enorme dano à arte teatral, que só se recuperou em 1660, com a volta de Charles II ao poder. Entretanto, as peças shakespearianas não eram as preferidas na Restauração. Paulatinamente, a partir de 1769, com as famosas comemorações do Jubileu do aniversário de Shakespeare em Stratford promovidas pelo ator David Garrick se inicia a ascensão de Shakespeare como poeta nacional e, com o passar do tempo, como poeta global. Ele é aclamado como um excepcional criador de personagens que marcaram indelevelmente as literaturas e as culturas anglo-saxônicas e mundiais. O próprio Shakespeare passa de criador a criatura na literatura popular, anunciante dos mais diversos produtos e vendedor de outros como os vários tipos de souvenirs. Este ensaio propõe traçar a mudança de status de Shakespeare como autor, do seu relativo esquecimento no período da Restauração para o seu atual prestígio nacional e global devido à sua excepcional capacidade criativa, e apontar para a outra fase da sua trajetória - a de criador de várias obras à criatura de vários criadores.

PALAVRAS-CHAVE: Shakespeare; trajetória; prestígio; criador; criatura. 


\section{SHAKESPEARE: creator and creature}

\section{ABSTRACT}

During the apex and prestige of the theatre in the Elizabethan and Jacobean eras, William Shakespeare (1564-1616) was an author among many. After he retired in 1611, other playwrights went on writing plays which confirmed the well deserved reputation of excellence of this theatre. In 1623, the publication of the so-called First Folio, with the collection of all Shakespearean plays, kindled the interest in the playwright again. Nevertheless, the closing of the theatres in 1642 by the Puritan goverment caused enormous harm to the theatrical art, only recovering in 1660 with the return of Charles II to power. Shakespearean plays were not particularly popular during the Restoration. Slowly, from 1769 onwards, with the famous celebrations of the Jubilee of Shakespeare's birthday at Stratford organised by the actor David Garrick Shakespeare began to be praised as national poet, and gradually, as global poet. He ís acclaimed as an exceptional creator of characters marking the literatures in the Anglo-Saxon and world cultures in an indellible way. Shakespeare himself is transformed from creator into creature in popular literature, announcer of several products and seller of others such as souvenirs. This essay aims at showing Shakespeare's change of status as an author, from his relative disappearance during the Restoration to his actual national and world wide prestige owing to his outstanding creative capacity also pointing out another phase of his life - from creator of several works to creature by several creators.

KEYWORDS: Shakespeare; progress; prestige; creator; creature. 
'Tis he! 'Tis he!

The god of our idolatry!"

(David Garrick, Ode, 1)

“... bless thee! Thou art translated!"

(A Midsummer Night's Dream, 3.1.98)

\section{Introdução}

Em 1769, David Garrick, o maior ator inglês do século XVIII, por ocasião do jubileu em honra de Shakespeare, não hesitou em decretar que ele era "o deus da nossa idolatria" (DOBSON, 1995, p.217) ${ }^{1}$. No século XIX, o dramaturgo francês Alexandre Dumas, pai, em um ensaio datado de 1863 intitulado - "Como me tornei dramaturgo"- diz que "depois de Deus, Shakespeare foi quem mais criou." (GROSS, 2002, p.3). Um século mais tarde, em 1960, o escritor argentino Jorge Luis Borges coloca Shakespeare diante de Deus se queixando que após ter sido muitos homens gostaria de ser ele mesmo. Ao que o Criador responde, "sonhei o mundo como sonhaste tua obra, meu Shakespeare, e entre as formas de meu sonho estás tu, que como eu és muitos e ninguém.” (1999, p.202). E, no século XXI, o crítico americano Harold Bloom confessa "que prega Bardolatria como a mais benigna de todas as religiões ... Para mim, Shakespeare é Deus." (2011, p.77). Primeiramente apresentado como um deus pagão, depois colocado abaixo do Deus do cristianismo, a seguir, igual a Ele e, finalmente, O suplantando, estas declarações revelam o fascínio que o extraordinário talento criativo de Shakespeare exerceu desde o século XVIII não só sobre os ingleses como, paulatinamente, passou a exercer sobre atores, escritores e críticos dos mais diversos países até hoje.

As grandes criações shakespearianas são as suas personagens. Algumas, em determinados momentos e contextos históricos, se tornaram criaturas independentes do seu criador. O que irá acontecer com o passar dos anos e a sua fama crescente é que Shakespeare, a exemplo do que ele havia feito com Bottom, o artesão de Sonho de uma noite de verão, tam-

1 Esta e as demais traduções para o português são de minha responsabilidade. 
bém é transformado em criatura, com múltiplas faces, as mais inusitadas, o que se acentua com o passar dos séculos graças, também, ao desenvolvimento dos meios de comunicação e a sua influência na cultura popular. Este ensaio pretende apontar algumas destas transformações e sugerir que o dramaturgo não só não perdeu o seu status divino, como permanece ainda mais poderoso na cultura ocidental devido à sua transformação em criatura.

\section{Shakespeare, o criador}

No auge da popularidade do teatro elisabetano-jaimesco, William Shakespeare (1564-1616) era, segundo Martin Wiggins, "um autor como muitos outros; das aproximadamente 250 peças existentes escritas no período mais ou menos correspondente a sua carreira, ele escreveu trinta e oito." (2000, p.1). Depois que ele se aposentou, aproximadamente em 1611, dramaturgos como John Fletcher (1579-1625), seu parceiro Francis Beaumont (c1585-1616), Thomas Middleton (1580-1627) e Ben Jonson (1572-1637) continuaram a escrever peças que perpetuaram a merecida fama desse teatro.

Em 1623, a publicação do First Folio, que reunia 36 peças de Shakespeare, já que Pericles, Os dois primos nobres e Eduardo III não constavam, reacendeu o interesse pelo dramaturgo e uma segunda edição foi publicada em menos de 10 anos, mais precisamente, em 1632. Entretanto, após a deposição e morte de Carlos I, o fechamento dos teatros decretado pelo governo puritano de Oliver Cromwell em 1642 causou um enorme dano à arte dramática inglesa, que só se recuperou graças à volta dos Stuarts em 1660. Com Carlos II, inicia-se o período conhecido na história inglesa como Restauração.

As mudanças sócio-culturais não poderiam deixar de afetar o teatro profundamente: segundo Hazelton Spencer, autor de Shakespeare Improved "não há dúvida de que no inicio da Restauração os autores preferidos eram Fletcher e Jonson.” (1963; p.41). Shakespeare só começou a ser aceito quando modificado para se ajustar às regras vigentes da arte dramática no final do século XVII. As adaptações continuaram durante o século XVIII, quando em 1769, com as famosas comemorações do Jubileu de seu aniversário promovidas em Stratford e depois reproduzidas em Londres pelo famoso ator shakespeariano David Garrick (1717-1779), se inicia a ascensão do poeta como "the god of our idolatry" que coincide com a crescente importância da sua pátria no cenário mundial. Segundo 


\section{Michael Dobson in The Making of the National Poet}

a transformação do status de Shakespeare do relativo esquecimento na Restauração para a sua preeminência nacional, na verdade, global... constitui uma das expressões culturais centrais da própria transição da Inglaterra do regime aristocrático dos Stuarts para o império comercial presidido pela dinastia dos Hanovers (1995, p.8).

Shakespeare se tornou, "em termos financeiros, a exportação mais bem sucedida da Grã-Bretanha; em termos culturais, suas peças têm influenciado culturas no mundo todo." (HOLLAND, 2007). E, em termos políticos e colonialistas,

o nome de Shakespeare figurava proeminentemente em discursos culturais coloniais; na verdade, a sua obra se tornou um meio de contextualizar e de determinar percepções e expectativas sobre a "missão civilizatória" da Grã-Bretanha e mais tarde de reações pós-coloniais a ela (SINGH, 1996, p.12).

Um autor tão universalmente famoso, a exemplo de outros escritores modernos, despertava enorme curiosidade como pessoa. Quem era ele? Onde viveu? Como e por que escreveu ? E conhecer suas obras simplesmente não bastava.

\section{0 criador: as biografias}

A figura de Shakespeare precisava se materializar, o que aconteceu na primeira edição das suas obras completas por Nicholas Rowe, em 1709. Além de ser o seu primeiro editor, Rowe foi, também, o seu primeiro biógrafo. O seu longo prefácio - "Some Account of the Life \& c. of Mr William Shakespear" - incluía a primeira biografia importante de Shakespeare já publicada (TAYLOR, 1990, p.74). Entretanto, foi no final do século XIX, que as suas biografias ganharam um enorme impulso com as publicações de Outlines of the Life of Shakespeare, de James Orchard Halliwell-Phillips em 1883, com 700 páginas, e A Life of William Shakespeare, de Sidney Lee, em 1898. Na primeira metade do século XX, mais precisamente em 1930, E.K. Chambers publica William Shakespeare: A Sudy of Facts and Problems, que servirá de estímulo para que Samuel Schoenbaum desenvolva uma extensa pesquisa sobre a vida de Shakespeare e a publique em etapas: em 1975, William Shakespeare: A Documentary Life; em 1977, uma edição abreviada, A Compact Documentary Life; e em 1991, é publicada Shakespeare's Lives: Authorship Questions. 


\section{Segundo David Bevington,}

Os métodos dos biógrafos são tão variados quanto os seus tópicos. Alguns, como Schoenbaum, coletam dados verificáveis e especulam sobre o seu significado somente com grande cautela. Para alguns outros, as inferências são feitas de fatos conhecidos contanto que sejam plausíveis (2010, p.13-14).

Tentando estabelecer um pequeno corte na imensidão de biografias de Shakespeare, podemos mencionar as mais recentes, acadêmicas e integrais como Ungentle Shakespeare, de Katherine Duncan-Jones (2001), que demistifica a figura do poeta apresentada em outras narrativas como doce e gentil, e The Life of William Shakespeare, de Lois Potter (2012), que acrescenta uma apreciação crítica da sua obra. Há, também, as que podem ser chamadas de "microbiografias" por se concentrarem em momentos da vida de Shakespeare como as de James Shapiro, que escreveu 1599. A Year in the Life of William Shakespeare (2005) e The Year of Lear. Shakespeare in 1606 (2015), e a de Charles Nicholl que focalizou Shakespeare apenas durante o tempo em que ele foi inquilino da família Mountjoy no período c.1603-5 em The Lodger Shakespeare. His Life on Silver Street (2008). Estas obras oferecem o que Shapiro denominou de "a slice of a writer's life" (2015, p.13). Há, ainda, as biografias "profissionais" que focalizam apenas a sua vida como autor e ator como Shakespeare's Professional Career, de Peter Thomson (1992) e Shakespeare the Player, de John Southworth (2000); e "as especulativas" que tentam adivinhar o que ele estava fazendo durante os anos de 1592 a 1598, como Shakespeare: the Lost Years, de E.A.J. Honigmann (1985), já que ainda não se encontrou nenhum documento que se referisse a ele durante esta época. Finalmente, há a que se apresenta como "uma biografia alternativa" com 25 ensaios distribuídos por três grupos que focalizam : o primeiro, a família; o segundo, amigos e vizinhos; e o terceiro, colegas e patrocinadores - intitulada The Shakespeare Circle, editada por Stanley Wells e Paul Edmondson (2016).

Mas, qual a importância e o valor de tantas biografias no que se refere à arte do Shakespeare criador? Biografias são válidas como ferramentas teóricas para a investigação do momento cultural em que o autor viveu e as influências que ele absorveu. Em seu artigo "Why Does Literary Biography Matter" publicado no Shakespeare Quarterly, Andrew Hadfield pondera que "as biografias só têm valor se sabemos porque as lemos e como planejamos usar o conhecimento que elas nos proporcio- 
nam. A biografia serve para nos ajudar a entender a literatura, que é o que realmente importa, não a vida em si." (2014, vol.65, n.4, 371-378). E é uma das melhores biógrafas de Shakespeare, Katherine Duncan-Jones, que, na última página do seu livro aconselha: "É muito melhor não ler ainda mais uma biografia, mas ler 〈o autor〉 ". (2002, p.284)

\section{0 criador e suas criaturas}

\section{Segundo F.E. Halliday, em Shakespeare and his Critics}

Shakespeare foi um duplo artífice, um criador não somente de poesia mas de pessoas, e neste caso nenhum outro poeta se aproxima dele. Nenhum outro escritor criou uma comparável companhia de homens e mulheres, humildes e aristocráticos, sisudos e alegres, cômicos e trágicos, nobres e patifes: de Launce a Cleópatra - a lista poderia ser ampliada indefinidamente. O que surpreende é que eles nada são além de palavras, e a surpresa final são as próprias palavras, a poesia que os faz viver. Porque eles são poesia. (1958, p.118).

É impossível discorrer sobre todas as personagens shakespearianas que criaram vidas próprias e se tornaram protagonistas de outras histórias nos romances, contos, dramas, poemas, filmes e, também, nas artes plásticas, música e ópera. $\mathrm{O}$ que seria assunto de um outro ensaio seria as chamadas "afterlives" de personagens shakespearianas. No seu livro Shakespearean Afterlives: Ten Characters With a Life of Their Own (2003), John O’Connor lista Romeu e Julieta, Henrique V, Cleópatra, Shylock, Ricardo III, Lady Macbeth, Hamlet, Kate e Próspero, como os que adquiriram vida própria e se afastaram do seu criador. E devemos nos lembrar que esse fenômeno não é recente: já em 1851-2, Mary Cowden Clarke narrou uma parte das vidas das suas heroínas em The Girlhood of Shakespeare's Heroines ("In a Series of Fifteen Tales"). O que causa espécie é o fato de O'Connor ter excluído as personagens femininas de $A$ tragédia de Hamlet, príncipe da Dinamarca que é, possivelmente, a peça que mais evidencia a pujança das personagens que motivam outras histórias e seguem outros destinos chegando até ao burlesco como em Hamlet Travestie, de John Poole (1810).

Além do próprio Hamlet, Ofélia sai das margens da peça para o centro das culturas erudita e popular, sendo uma das mais representadas heroínas shakespearianas não só pelos ficcionistas mas, também, pelos pintores, principalmente na Inglaterra do século XIX. Há dois belos trabalhos sobre as recriações de Ofélia por pesquisadores brasileiros: na 
literatura, por Leonardo Bérenger Alves Carneiro (UFRJ, 2014) e na pintura, por Cristiane Busatto-Smith (UFPR, 2007). Gertrudes e Cláudio são os protagonistas do romance Gertrude and Claudius, de John Updike (2000), e ela ganha voz no conto de Margaret Atwood "Gertrude Talks Back", onde confessa que foi a assassina do rei Hamlet. Outras personagens também ganham vida própria: Horácio é o herói de Horatio’s Version, de Alethea Hayter (1972) e Tom Stoppard dá protagonismo a dois personagens secundários da tragédia na sua peça Rozencrantz and Guildenstern Are Dead (1967).

Apaixonante e irresistível é Falstaff, que mereceu do grande crítico Harold Bloom um livro a exemplo do que ele já havia feito com Hamlet e o Rei Lear. Este Falstaff, personagem de duas peças históricas (Henrique $I V$, parte 1 e Henrique $I V$, parte 2) e uma comédia (As alegres comadres de Windsor) shakespearianas, ao mesmo tempo encantador e cruel, simpático e cínico, malandro e patético, mereceu ser recriado no drama, no romance, na gravura e na música. Já no início do século XVIII, mais precisamente em 1702, Sir John Dennis publicou uma comédia intitulada The Comical Gallant; or, The Amours of Sir John Falstaffe: A Comedy, uma tentativa típica da época de reescrever as peças shakespearianas para "melhorá-las". Outra tentativa dramatúrgica de reviver Falstaff no século XVIII foi a de William Kenrick, autor de Falstaff's Wedding: A Comedy, Being a Sequel to the Second Part of the Play of King Henry the Fourth. Written in Imitation of Shakespeare (1766). A peça foi um fracasso no teatro, mas bem sucedida na vendagem do texto.

Falstaff também aparece no século XVIII em relatos em prosa sobre bandidos e salteadores de estradas, sendo um deles. Entretanto, é no século XIX que ele ganha uma grande notoriedade não só porque Robert Barnabas Brough publica a sua biografia se baseando em "fontes autênticas" em 1858 - The Life of Sir John Falstaff: With a Biography of the Knight from Authentic Sources - mas, também, porque ele passa a ser representado nas artes plásticas, sendo o livro ilustrado pelo famoso George Cruikshank (1792-1878), com grande destaque para as suas gravuras. Outra importante transposição da personagem do drama para a ficção é o excelente e premiado romance de Robert Nye (1976) intitulado Falstaff onde a personagem, aos 81 anos, narra as suas memórias. E, no século XXI, Falstaff se encontra na companhia dos zumbis no romance de Lynn Murray Falstaff Vampire Files (2011). Este breve relato sobre a "afterlife" de Falstaff não poderia ser encerrado sem referência à famosa ópera Falstaff de Giuseppe Verdi (1893). 
O doce e melancólico Bobo de Rei Lear passa a ser indecente, debochado e altamente manipulador no livro Fool, de Christopher Moore (2010), que transforma a tragédia em uma narrativa extremamente irreverente e até profana para a surpresa e o desespero dos mais sérios estudiosos shakespearianos.

Não só o drama de Shakespeare fornece personagens que ganham vida própria; a poesia, também. A Dark Lady dos sonetos ganha um conto de Bernard Shaw, "The Dark Lady of the Sonnets" (2005), e é uma importante personagem no romance de Anthony Burgess Nothing like the Sun (1964). E marca presença em outras narrativas.

\section{0 criador como criatura}

Depois de ter criado tantas criaturas - 1378 papéis responsáveis por 34.895 falas (CRYSTAL \& CRYSTAL, 2005, p.39) - o criador se torna uma. Como já foi mencionado, as peças de Shakespeare não eram muito representadas na Restauração; no século XVIII, elas só alcançavam o palco sendo modificadas para agradar ao gosto do público da época. $\mathrm{Na}$ "Check List of the Adaptations of Shakespeare's Plays 1660-1820" de George C. Branam, nota-se que vários títulos das peças geralmente acrescentam que são "adaptações, imitações e/ou adições". Como exemplo mais significativo pode-se citar a adaptação de Macbeth em 1674, por William Davenant: Macbeth a Tragedy. With All the Alterations, Amendments, Additions, and New Songs. (1956, p.186). Merece ser destacado o acréscimo de "new songs".

É interessante assinalar que as primeiras presenças de Shakespeare como personagem encontram-se no teatro no final do século XVII, personificando o Espectro dele mesmo, aparecendo nas suas peças alteradas e fazendo comentários sobre as suas próprias, tomando posições em relação à política da época, pregando nacionalismo ou exortando os seus compatriotas a honrarem a pátria em tempos de guerra. Possivelmente, a primeira presença do Espectro de Shakespeare foi no Prólogo da adaptação de Tróilo e Créssida por John Dryden, em 1679. É interessante registrar que, vinte e dois anos mais tarde, na adaptação de $O$ mercador de Veneza (1701) por George Granville, os Espectros de Shakespeare e Dryden aparecem juntos no Prólogo denunciando um tipo de comédia que consideram "baixa e transgressora." ( SPENCER, 1965, p.348-349).

Na metade do século XVIII o Espectro abandona o teatro para figurar na ficção. Em 1755 é publicado, em dois volumes, o texto Memoirs 
of the Shakespear's-Head in Covent-Garden: By the Ghost of Shakespear. Segundo Michael Dobson

Neste primeiro romance a incluir Shakespeare como protagonista, assim como nas adaptações contemporâneas, Shakespeare, através da purgação da sua própria vulgaridade elisabetana, ressurge como moralista pra censurar as transgressões da Londres georgiana (1995, p.211).

Shakespeare, então, começa a aparecer como personagem principal de biografias ficcionalizadas, romances, peças teatrais, filmes e séries televisivas. Ele também será coadjuvante nas obras centradas na sua família - seu irmão Edmundo, sua esposa Anne, suas filhas Judith e Susanna e até do seu pequeno filho Hamnet. As narrativas mostram diversas facetas da personalidade do Bardo, na grande maioria, elogiosas, todas podendo ser respaldadas pela declaração de Anthony Burgess que, no prefácio do seu livro Shakespeare, declara: "O que reivindico aqui é o direito de cada amante de Shakespeare que já viveu pintar o seu próprio retrato do homem." (1964, p.9).

E um retrato encantador de Shakespeare foi pintado pelo grande crítico Stanley Wells em um pequeno livro intitulado Coffee With Shakespeare (2008), um exemplar da chamada "narrativa de viagem no tempo", que transporta Shakespeare para o presente (FRANSSEN, 2016, p.1). Ele consiste em uma longa entrevista - propiciada pelo milagre de trazer o Bardo para o século XXI - entre Shakespeare e um entrevistador imaginário. Uma pequena introdução ao livro apresenta os fatos mais relevantes da vida de Shakespeare e a entrevista começa: as perguntas são impressas em cor verde e as respostas em marron. $\mathrm{O}$ entrevistador termina lamentando não ter tido tempo de perguntar tudo o que queria. Neste livro, metade biografia e metade ficção, o criador de tantas personagens se transforma em uma, que recusa a oferta de um café e pede vinho (p.33) e é informado de tudo o aconteceu depois da sua morte... E, às vezes, até se surpreende...

\section{As várias faces da criatura}

Como já foi mencionado, gradualmente a personagem Shakespeare aparece no teatro e na ficção; abraçado pela cultura popular, ela aparecerá no cinema, na televisão, nos quadrinhos, nas literaturas infantil e juvenil. Devido ao limitado escopo deste ensaio, vou destacar rapidamente apenas sua presença na ficção e no teatro. 
Ótimos exemplos de romances protagonizados por Shakespeare são os livros Nothing Like the Sun. A Story of Shakespeare's Love-life, de Anthony Burgess (1975), Will, de Grace Tiffany (2004), o igualmente intitulado Will, de Cristopher Rush (2007) e The Secret Life of William Shakespeare, de Jude Morgan (2012). Shakespeare's Dog, de Leon Rooke (1983) mostra uma fase da vida de Shakespeare em Stratford narrada pelo seu cachorro Hooker que o vê como um homem bastante comum.

Deve-se destacar que Shakespeare, sempre aparecendo no teatro como a figura do Espectro desde o final do século XVIII, só vai conquistar o papel de protagonista no começo do século XIX, atravessando o Canal da Mancha. "Isto se deve ao dramaturgo francês Alexandre Duval, cuja peça curta Shakespeare amoureux (1804) mostrou que Shakespeare, o homem, era um assunto válido para o teatro." (FRANSSEN, 2017, p. 36). É o que se comprova, por exemplo, na peça Bingo: Scenes of Money and Death (1974), de Edward Bond. Nela, um angustiado Shakespeare, infeliz em casa e com um mau relacionamento com a filha Judith, atormentado por não se opor ao plano de cercamento dos campos comuns de Stratford (Welcombe), o que prejudicaria a população pobre, conversa com Jonson em uma taverna e dele obtém o veneno com o qual se suicida. A motivação para escrever sobre este episódio da vida de Shakespeare foi, segundo Bond, o fato da maioria das biografias de Shakespeare o ignorarem (1974, p.xv).

Deve-se notar que a personagem Shakespeare passa de protagonista a coadjuvante nas narrativas e peças que focalizam membros da sua família: a esposa, em Mrs. Shakespeare: The Complete Works, de Robert Nye (1993), traduzido no Brasil como $O$ relato íntimo de Madame Shakespeare (2005), e a filha mais nova em My Father Had a Daughter, com o subtítulo "Judith Shakespeare's Tale", de Grace Tiffany (2003). Tanto Anne Hathaway como a sua filha Judith já haviam inspirado livros no século XIX. A relação de Anne com o marido, que viveu em Londres a maior parte da sua vida de casados e lhe deixou como herança a "segunda melhor cama", inspirou diversas interpretações como a peça intitulada Shakespeare's Will, de Vern Thiessen (2005). No caso de Judith, o fato de ter sobrevivido ao seu irmão gêmeo Hamnet, morto aos onze anos, e de ter se casado com um jovem marcado por um escândalo sexual a faz uma atraente figura de romance. A filha mais velha, Susanna, que tinha por marido o respeitado médico John Hall, é a protagonista da peça The Herbal Bed, de Peter Whelan (1999). Shakespeare aparece aqui, mas não 
é visto nem pronuncia palavra; a ação termina com ele sendo levado para a casa da sua filha para ser tratado da sífilis que contraiu quando morava em Londres.

Os irmãos de Shakespeare também são retratados em alguns romances que ele não protagoniza. Edmundo, que era ator e morreu aos 27 anos em Londres, é apresentado com mais nitidez nas biografias literárias. Gilbert foi reconstruído como inimigo do irmão e amante da sua esposa em romances populares, enquanto o apagado Richard, mal delineado, aparece muito recentemente (2017) como o herói de Fools and Mortals, de Bernard Cornwell. Até o pequeno filho de Shakespeare, Hamnet, é assunto do livro Will Shakespeare's Little Lad (1916) para o público infanto-juvenil, de Imogen Clark.

\section{Shakespeare? Que Shakespeare?}

Quando se discute o autor Shakespeare, naturalmente surge a antiga questão da autoria, ("the authorship question"), que desde a metade do século XIX passou a ser divulgada e nunca deixou de ser discutida. Nomes importantes da cultura ocidental como os escritores Henry James e Mark Twain, o psicanalista Sigmund Freud, os atores-cineastas Charlie Chaplin e Orson Welles, os atores shakespearianos do passado Leslie Howard e John Gielgud, e os do presente, Derek Jacobi e Mark Rylance não acreditam que William Shakespeare seja o autor das peças do Primeiro Fólio. Nas 367 páginas do seu livro Contested Will. Who Wrote Shakespeare? (2010), James Shapiro cita, entre os nomes mais recentemente propostos, Francis Bacon, Christopher Marlowe, John Donne, The Earl of Derby, The Earl of Oxford (Edward de Vere) e as mulheres Mary Sidney (Countess of Pembroke) e até a própria rainha Elisabete... Segundo Shapiro, mais de 50 nomes foram propostos e, enquanto ele escrevia o livro, publicado em 2010, mais quatro candidatos apareceram...E deve-se acrescentar o filme Anonymous (2011), de Roland Emmerich.

Nesta "mad erudition", como a denomina Douglas Lanier em Shakespeare and Modern Popular Culture (2002, p. 133), merece mais atenção para o propósito deste ensaio a peça I Am Shakespeare, subintitulada "A Comedy of Shakespearean Identity Crisis", de Mark Rylance. Ele nasceu em 1960; é um grande ator shakespeariano da atualidade e foi diretor do Shakespeare's Globe por dez anos, mais precisamente, de 1995 até 2005. A peça foi apresentada pela primeira vez em um festival de teatro em Chichester, em 2007, quando foi lançado 
o manifesto A Declaration Of Reasonable Doubt On The Authorship Of William Shakespeare's Work. Publicada em 2012 e 2013, a peça dá voz a candidatos como Francis Bacon, Edward de Vere, Mary Sidney e ao ator William Shakspar. E é esta personagem, negada por Rylance, que parece contrariar a tese do autor: "Sou apenas um homem comum como vocês com uma grande imaginação. Apenas apreciem as peças. Que importa quem as escreveu?" (RYLANCE, 2013, p.83). E, apesar de Rylance demonstrar a sua discordância em relação a Shapiro na introdução da peça, a fala da sua personagem Shakspar nos remete à opinião do pesquisador quando este afirma: "O que acho mais desalentador sobre a tese de que Shakespeare de Stratford não tinha a experiência de vida para escrever as peças é que ela diminui o próprio fato que o faz tão excepcional: a sua imaginação." (2010, p.313).

\section{Shakespeare espaçoso}

Shakespeare, tanto o criador como a criatura, ocupa - podemos arriscar - todos os espaços culturais, tanto eruditos como populares. Além da reconstrução do Shakespeare's Globe em Londres, "outros teatros renascentistas tangencialmente associados com Shakespeare foram construídos no mundo todo nos mais diversos lugares" (LANIER, 2006, p.151), como Japão, Tchecoslováquia, Austrália, Alemanha, e os estados de Virginia, Texas, Utah e California, nos Estados Unidos. Estes são os abrigos da cultura erudita onde as peças do criador são apresentadas e a sua memória de expoente do teatro mundial é cultivada; alguns, claramente, têm como objetivo maior popularizar a sua obra, como é o caso do Shakespeare's Globe, que tenta aproximar o público contemporâneo do elisabetano-jaimesco.

Grandes espaços geográficos também remetem a Shakespeare, pois, nos Estados Unidos, inúmeras cidades são nomeadas não só com nomes de suas personagens como de lugares onde se desenrolam as tramas de suas peças, Um mapa shakespeariano dos Estados Unidos destaca estas localidades (DOBSON \& WELLS, 2005, p. 505). Entre as personagens femininas podemos citar Bianca, Créssida, Cordélia, Cleópatra, Desdêmona, Julieta, Miranda, Ofélia, Pórcia, Rosalinda e Miranda. Hamlet é a personagem mais contemplada entre as cidades que homenageiam as personagens masculinas, emprestando o seu nome a quatro delas. Seguem-se Romeu, Otelo, Sebastião, Ariel e a conhecidíssima Orlando. Até os vilões Iago e Ricardo são incluídos. Os lugares que se remetem a peças 
de Shakespeare, como, por exemplo, Atenas, Tróia, Roma, Verona, Viena, Dinamarca, Escócia, Veneza, também são cidades americanas:

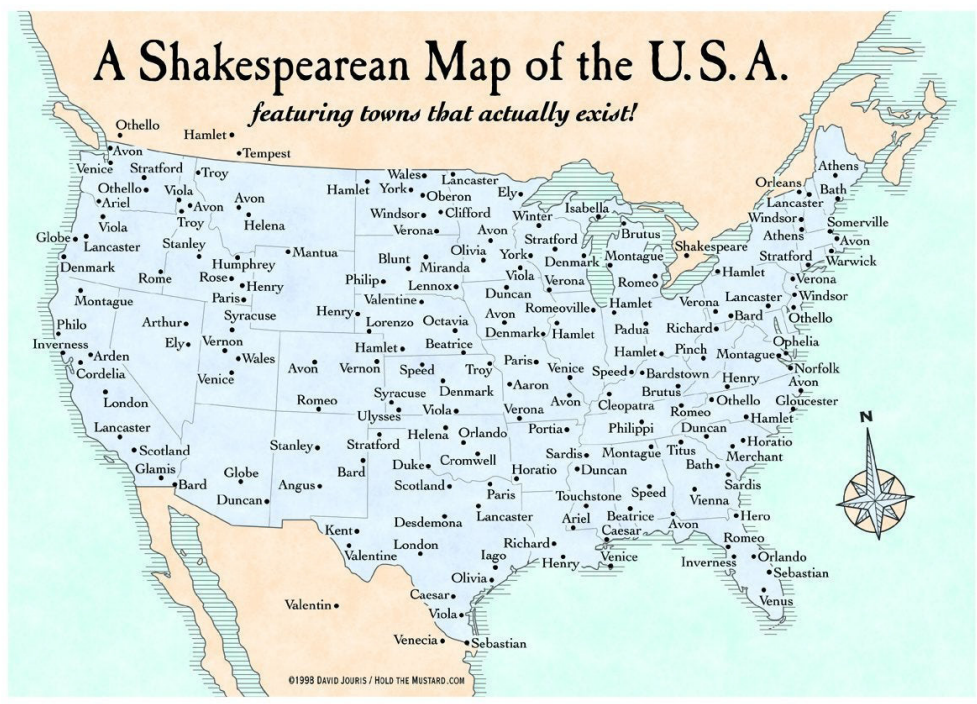

Figura 1. Mapa dos Estados Unidos com as cidades cujos nomes remetem ao universo shakespeariano. (In: DOBSON \& WELLS, 2005, p. 505)

E como se a terra não fosse suficientemente grande para conter a enormidade da sua obra, esta também se lança no espaço. O último filme da série Star Trek (1991) cita Shakespeare no seu subtítulo - "The Undiscovered Country" - uma referência a Hamlet (3.1.79). Sabemos que esta tragédia foi traduzida para o "klingon", língua inventada para a série. Entretanto, é a astronomia que nos fornece as provas mais contundentes de que Shakespeare foi para o espaço. Literalmente. Em_1851, o astrônomo William Lassell iniciou a prática de batizar os satélites de Urano com nomes de personagens shakespearianas. "As convenções de nomenclatura organizadas pela União de Astronomia Internacional, em 1919, continuaram com a prática, que continuará à medida que novos satélites forem descobertos." (CRYSTAL \& CRYSTAL, 2005, p.43).

Das vinte e uma luas de Urano (até agora) dezoito foram batizadas com nomes de personagens shakespearianas: Próspero, Ariel, Caliban e Sycorax de A tempestade; Oberon, Titânia e Puck de Sonho de uma noite 
de verão; Romeu e Hamlet. E temos ainda famosas personagens femininas como Bianca, Créssida, Desdemona, Julieta, Cordélia, Ofélia e Pórcia, girando acima de nossas cabeças...

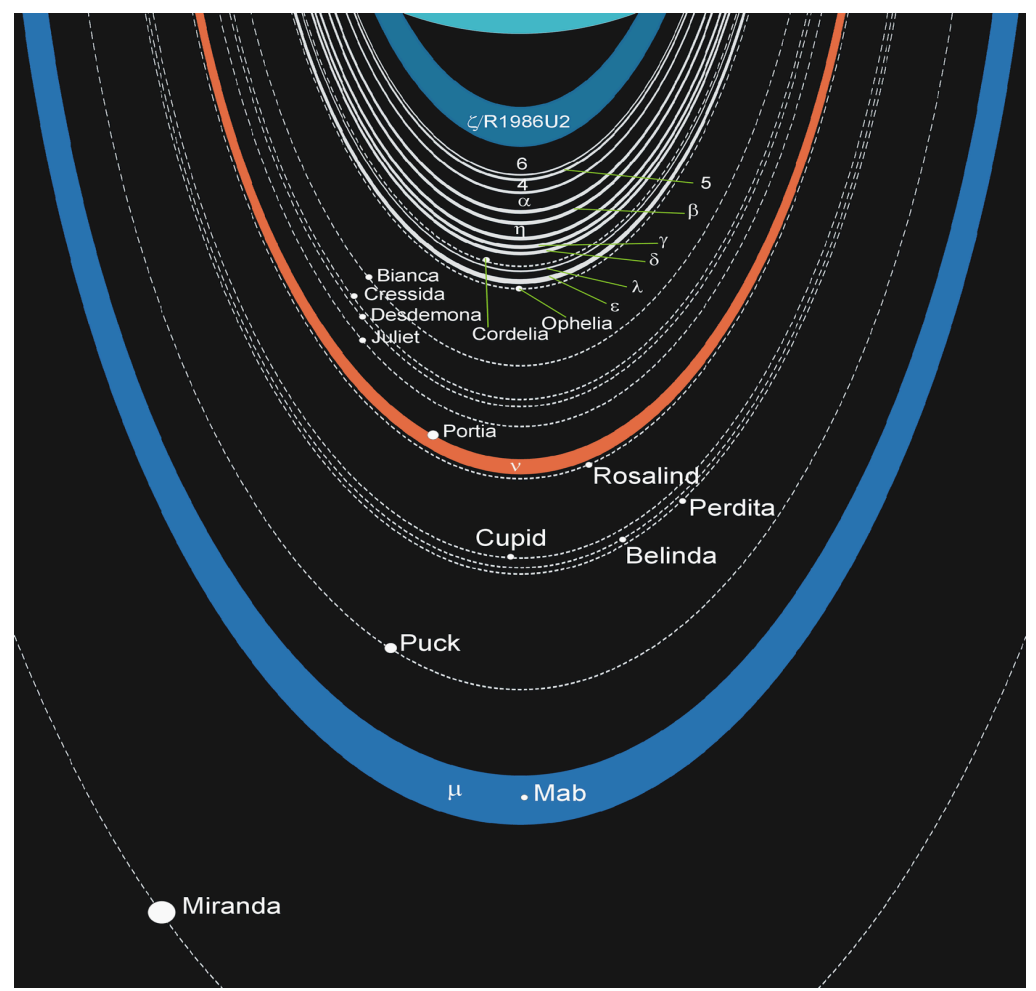

Figura 2. https://upload.wikimedia.org/wikipedia/commons/e/e1/Uranian_rings_scheme.png

Shakespeare está presente na nossa terra e no nosso céu, e na nossa cultura capitalista - nas lojas de souvenirs - também. Ele se tornou um vendedor global e suas criaturas, agentes publicitários da sua marca, que vende de tudo: desde a Coca-Cola universal até a nossa brasileiríssima sobremesa de queijo com goiabada anunciada há algum tempo na televisão como "Romeu e Julieta com final feliz", além do sabonete "Macbath". E ele próprio, como já foi visto, de criador passou também a ser criatura, e até criaturinha, transformado em um patinho de borracha com uma folha branca debaixo da asa onde se lê "to quack or not to quack"...[Figura 3]. 


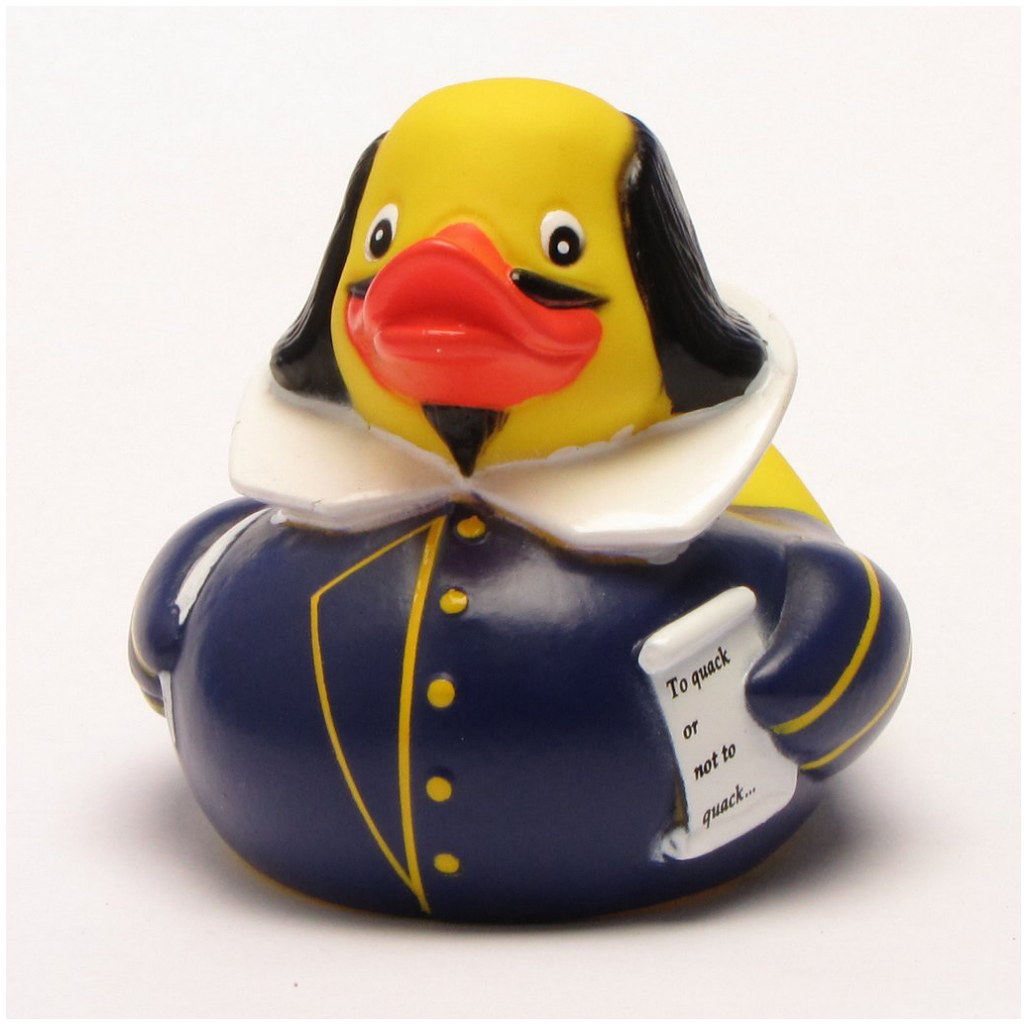

Figura 3. https://www.amazon.com/Duckshop-Shakespeare-Rubber-Duck/dp/B00E651MX4

\section{Conclusão}

Alçado à divindade através dos tempos por diferentes admiradores de diferentes profissões - $\mathrm{o}$ ator Garrick, os escritores Alexandre Dumas, pai, e Jorge Luis Borges, e o crítico Harold Bloom - Shakespeare continua fazendo jús à qualificação desde o século XVIII. Dotado de poder divino, ele está em todos os lugares: as diversas edições das suas peças, sonetos e poemas narrativos fazem parte dos acervos das bibliotecas como também estão nas estantes das livrarias onde ocupam lugar de destaque; sua obra é discutida nas universidades e nos congressos, e vista nos teatros. Também, a partir século XVIII, assim como as suas criaturas, ele 
igualmente foi se transformando em uma, protagonista e coadjuvante de peças e romances, solicitado tanto pela cultura popular como pela indústria cultural. Shakespeare, o criador, convive muito bem com a sua outra face: a de criatura.

\section{REFERÊNCIAS BIBLIOGRÁFICAS}

ATWOOD, Margaret. Good Bones and Simple Murders. London: Virago, 2007. BATE, Jonathan. Soul of the Age. London; Picador, 1998.

BEVINGTON, David. Shakespeare and Biography. Oxford: Oxford University Press, 2010.

BLOOM, Harold. The Anatomy of Influence. Literature as a Way of Life. New Haven and London: Yale University Press, 2011.

BOND, Edward. Bingo. Scenes of Money and Death. London: Methuen, 1974.

BORGES, Jorge Luis. Obras Completas. Vol. 2. Trad. Josely Vianna Baptista. São Paulo : Editora Globo, 1999, p.202.

BRANAM, George C. Eighteenth-Century Adaptations of Shakespearean Tragedy. Berkeley and Los Angeles: University of California Press, 1956.

BROUGH, Robert Barnabas. The Life of Sir John Falstaff: With a Biography of the Knight from Authentic Sources. Illustrated by George Cruikshank. Cambridge: Cambridge University Press, 2013 [1858]. [digitally printed version]

BURGESS, Anthony. Nothing Like the Sun. London:Vintage, 1992.

BURGESS, Anthony. Shakespeare. 1st edition: 1970. New York: Carroll \& Graff Publishers, 2012.

BUSATTO-SMITH, Cristiane. Representações da Ofélia de Shakespeare na Inglaterra Vitoriana: um Estudo Interdisciplinar. Tese de doutorado. Curitiba: UFPR, 2007.

CARNEIRO, Leonardo Bérenger Alves. "Thy name is woman": a (re)construção das identidades femininas em narrativas de Hamlet. Tese de Doutorado. Rio de Janeiro: UFRJ, 2014.

CLARK, Imogen. Will Shakespeare's Little Lad. The Story of Hamnet. 1st edition 1897. Maryland: Wildside Press, 2011. 
CLARKE, Mary Cowden. The Girlhood of Shakespeare's Heroines («In a Series of Fifteen Tales"). In: WELLS, Stanley. Shakespeare for All Time. Oxford: Oxford University Press, 2003, p.313.

CORNWELL, Bernard. Fools and Mortals. New York: HarperCollins, 2017.

CRYSTAL, David \& CRYSTAL, Ben. The Shakespeare Miscellany. London: Penguin Books, 2005.

DENNIS, Sir John. The Comical Gallant; or, The Amours of Sir John Falstaffe: A Comedy. In: SPENCER, Hazelton. Shakespeare Improved. New York: Fredick Ungar Publishing Co., 1927, p.344-350.

DOBSON, Michael. The Making of the National Poet. Shakespeare, Adaptation, and Authorship, 1660-1769. Oxford: Clarendon Press, 1995.

DOBSON, Michael \& WELLS, Stanley (eds). The Oxford Companion to Shakespeare. Oxford: Oxford University Press, 2005.

DUNCAN-JONES, Katherine. Ungentle Shakespeare. Scenes from his Life. London: Arden Shakespeare, 2002.

DUVAL, Alexandre. Shakespeare Amoureaux. In O'SULLIVAN, Jr. (ed). Shakespeare's Other Lives. An Anthology of Fictional Depictions of the Bard. Jefferson, North Carolina: McFarland \&Company, Inc., Publishers, 1997, p. 26-43. EDMONDSON, Paul; WELLS, Stanley. The Shakespeare Circle. An Alternative Biography. Cambridge: Cambridge University Press, 2016.

EMMERICH, Roland, dir. Anonymous. Com Rhys Iphans e Vanessa Redgrave. Distribuição da Columbia Pictures. EUA, 2011.

FRANSSEN, Paul. Shakespeare's Literary Lives. The Author as Character in Fiction and Film. Cambridge: Cambridge University Press, 2016.

GROSS, John (ed). After Shakespeare. An Anthology. Oxford: Oxford University Press, 2002.

HADFIELD, Andrew. Why Does Literary Biography Matter? Shakespeare Quarterly, Washington, v. 65, n. 4, p.371-378, Winter 2014.

HALLIDAY, F.E. Shakespeare and his Critics. London: Robert Bentley, Inc., 1953.

HAYTER, Alethea. Horatio's Version. London: Faber \& Faber, 1972.

HOLLAND, Peter. Shakespeare. VIP Very Interesting People. Oxford: Oxford University Press, 2007.

HONIGMANN, E.A. J. The Lost Years. Manchester: Manchester University Press, 1998. 
KENRICK, William. Falstaff's Wedding. Mentioned in Michael Dobson, The Making of the National Poet. Shakespeare, Adaptation, and Authorship, 16601679, p. 214 .

LANIER, Douglas. Shakespeare and Modern Popular Culture. Oxford: Oxford University Press, 2006.

MOORE, Christopher. Fool. New York, London, Toronto, Sidney: Harper, 2010. MORGAN, Jude. The Secret Life of William Shakespeare. London: Headline Review, 2012.

MURRAY, Barbara. Restoration Shakespeare: Viewing the Voice. Madison.Teaneck: Farleigh Dickinson University Press; London: Associated Presses, 2001.

MURRAY, Lynne. Falstaff Vampire Files. Nashville, NT. Pearlsong Press, 2011

NICHOLL, Charles. The Lodger: his life on Silver Street. New York: Viking, 2008.

NYE, Robert. Falstaff. First edition 1976. New York: Arcade Publishing, 2012.

NYE, Robert. O relato intimo de Madame Shakespeare. Trad. Lidia Luther. São Paulo: Geração Editorial, 2005.

NYE, Robert. The Late Mr Shakespeare. Harmondsworth: Penguin Books, 2000.

O'CONNOR, John. Shakespearean Afterlives: Ten Characters With a Life of Their Own Cambridge: Icon Books Ltd., 2003.

O’SUlLIVAN, Jr. Maucrice J., ed. Shakespeare's Other Lives. An Anthology of Fictional Depictions of the Bard. Jefferson, North Carolina: McFarland \& Company, Inc., Publishers, 1997.

POTTER, Lois. The Life of William Shakespeare. A Critical Biography. Oxford: Wiley- Blackwell, 2012.

RYLANCE, Mark. I Am Shakespeare. London: Nick Hern Books, 2013.

ROOKE, Leon. Shakespeare's Dog. New York: The Echo Press, 1986.

RUSH, Christopher. Will. Ist edition 2007. Edinburgh: Polygon, 2014.

SHAW, Bernard. The Dark Lady of the Sonnets. In: O'Sullivan, Jr., Maurice J., eds. Shakespeare's Other Lives. An Anthology of Fictional Depictions of the Bard. Jefferson, North Carolina: McFarland \& Company, Inc., Publishers, 1997, p. 92-103.

SCHEIL, Katherine West. Imagining Shakespeare's Wife. The After life of Anne Hathaway. Cambridge: Cambridge University Press, 2018. 
SCHOENBAUM, S. Shakespeare's Lives. New Edition. Oxford: Clarendon Press, 1991.

SHAPIRO, James. 1599. A year in the life of William Shakespeare. London: Faber and Faber, 2006.

SHAPIRO, James. Contested Will. Who wrote Shakespeare? London: Faber and Faber, 2010.

SHAPIRO, James. The Year of Lear. Shakespeare in 1606. New York, London, Toronto, Sydney, New Delhi: Simon \& Schuster, 2015.

SINGH, Jyotsna G. Colonial Narratives / Cultural Dialogues. London and New York: Routledge, 1996.

SOUTHWORTH, John. Shakespeare the Player. A Life in the Theatre. Stroud: Sutton Publishing, 2002.

SPENCER, Hazelton. Shakespeare Improved. The Restoration Versions In Quarto and On the Stage. New York: Frederick Ungar Publishing Company, [1927], 1963.

STOPPARD, Tom. Rosencrantz \& Guildenstern Are Dead. London: Faber and Faber, 1967.

TAYLOR, Gary. Reinventing Shakespeare. A Cultural History from the Restoration to the Present. London: The Hogarth Press, 1990.

THIESSEN, Vern. Shakespeare's Will. Toronto, Ontario: Playwrights Canada Press, 2005.

THOMSON, Peter. Shakespeare's Professional Career. Cambridge: Cambridge University Press, 1992.

TIFFANY, Grace. My Father Had a Daughter. Judith Shakespeare's Tale. New York: Berkley Books, 2003.

TIFFANY, Grace. Will. New York: Berkley Books, 2004.

UPDIKE, John. Gertrude and Claudius. New York: Random House, 2012.

WELLS, Stanley. Coffee with Shakespeare. London: Duncan Baird Publishers, 2008.

WHELAN, Peter. The Herbal Bed. New York: Dramatist Play Service, Inc., 1999.

WIGGINS, Martin. Shakespeare and the Drama of his Time. Oxford: Oxford University Press, 2000. 


\section{REFERÊNCIAS ICONOGRÁFICAS}

Figura 2. As luas de Urano. Disponível em: https:/upload.wikimedia.org/wikipedia/commons/e/e1/Uranian_rings_scheme.png. Acesso em 21/11/2019.

Figura 3. Patinho de borracha. Disponível em: https://www.amazon.com/Duckshop-Shakespeare-Rubber-Duck/dp/B00E651MX4. Acesso em 21/11/2019.

Recebido em: 31/07/2019

Aceito em: 30/11/2019 